\title{
Mitigation of Voltage Sags in CIGRE Low Voltage Distribution Network
}

\author{
Ghullam Mustafa Bhutto ${ }^{1,2}$, Birgitte Bak-Jensen ${ }^{1}$, Pukar \\ Mahat $^{1}$ \\ ${ }^{1}$ Department of Energy Technology, Aalborg University, \\ Denmark \\ ${ }^{2}$ Department of Electrical Engineering Quaid-E-Awam \\ University of Sciences \& Technology, Nawabshah, Pakistan \\ gmu@et.aau.dk
}

\author{
P.f Ribeiro ${ }^{3}$ \\ ${ }^{3}$ Eindhoven University of Technology, Netherlands
}

\begin{abstract}
Any problem in voltage in a power network is undesirable as it aggravates the quality of the power. Power electronic devices such as Voltage Source Converter (VSC) based Static Synchronous Compensator (STATCOM), Dynamic Voltage Restorer (DVR) etc. are commonly used for the mitigation of voltage problems in the distribution system. The voltage problems dealt with in this paper are to show how to mitigate voltage sags in the CIGRE Low Voltage (LV) test network and networks like this. The voltage sags, for the tested cases in the CIGRE LV test network are mainly due to three phase faults. The compensation of voltage sags in the different parts of CIGRE distribution network is done by using the four STATCOM compensators already existing in the test grid. The simulations are carried out in DIgSILENT power factory software version 15.0.
\end{abstract}

Index Terms-Wind Turbine Generator (WTG), Photovoltaic (PV), Voltage Source Converter (VSC), Static Compensator (STATCOM), Battery Energy Storage System (BESS) and mitigation of voltage sags.

\section{INTRODUCTION}

Power quality, reliability and stability are the prime requirement of modern power systems. It is the aim of the utilities to continuously deliver the power to the customers at constant voltage and constant frequency. The quality of the power might be lost due to the deviations in the voltage and frequency of the network. Deviations are due to faults, coupling transients, lightening etc. The modern power industry comprise of VSC based equipments which are very sensitive to voltage sags/swells. Sag or swells in the voltage may cause tripping of such sensitive equipments which can cause damage to the production of plants. This may lead to huge economical loss. An increase or decrease of the voltage in power network requires a desired amount of absorbed or injected reactive power to counteract the disturbance. The flow of reactive power through the lines/cables reduces the power transfer capability of the lines/cables as well as increases the current which leads to increased losses [1]. It is therefore, necessary to control the voltage and reactive power of the distribution network in order to ensure stable operation of the power system and operate the lines within their safe thermal loading limits.

Custom power devices can be used in this regard. Customs devices are the power electronics based devices such as (DVR), Distribution Static Compensator (D-STATCOM) etc. which are used to improve the quality of the power in electrical distribution network [2]. The VSC is a main component in these kinds of devices. Benefits of using VSCs are sinusoidal currents, controllable reactive power to regulate power factor or bus-voltage level and independent control of active and reactive power [3].

A test distribution network set up by CIGRE comprising WTG, PV solar generation units, two batteries and STATCOMs comprising VSCs at different locations has been chosen for the study. The single line diagram of this distribution system is shown in "Fig." 1 . The introduction of different components of this network is described and the detailed data concerning the bus bars, cables/lines and the loads are given in [4].

The CIGRE network is modeled in DIgSILENT power factory software version 15.0. STATCOM controllers for both the PV systems have been developed in order to control oscillations in the AC and DC link voltage by injecting or absorbing the desired amount of the reactive power. The controllers for the Battery Energy Storage Systems (BESS) are developed and are able to charge/discharge the batteries at different charging rates and deliver reactive power when voltage in the network decreases. The BESS controllers are developed in such a way that they counteract voltage and frequency disturbances by receiving/delivering active and reactive powers at same time. The detailed methods of modeling these controllers together with mathematical representations are already described by the author in [5]. 


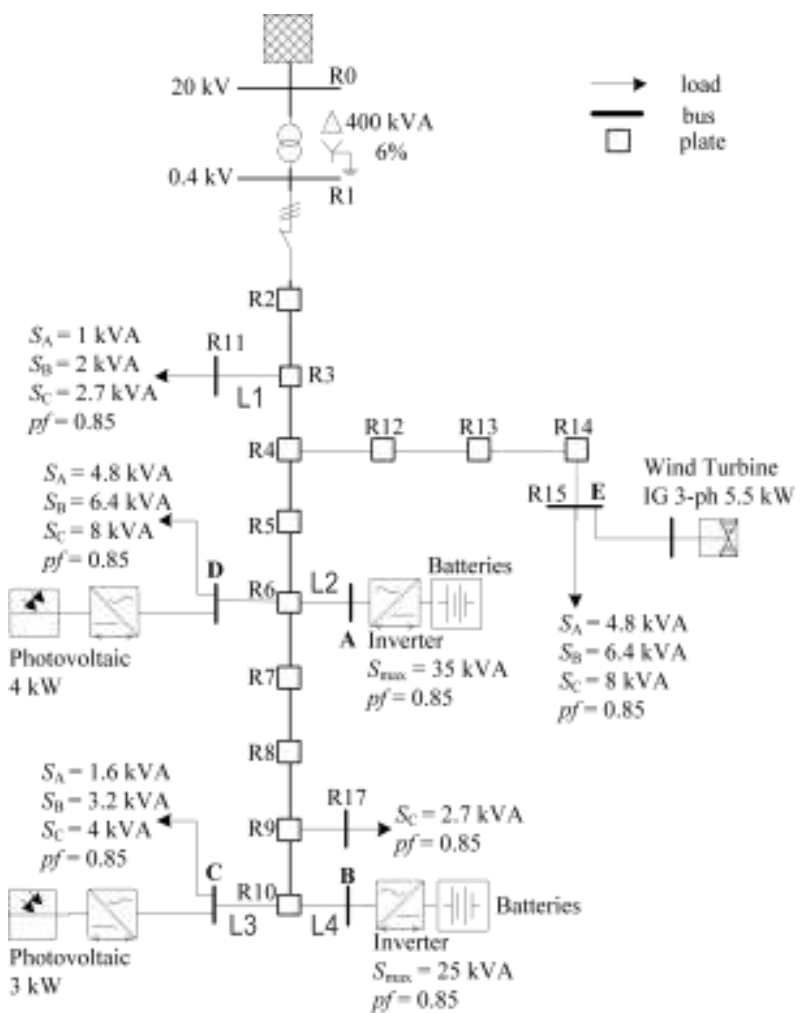

Figure 1. The single line diagram of LV CIGRE distribution system

The four controllers (i.e. two D-STATCOM controllers for PV units and two BESS STATCOM based controllers for the batteries) are used for the mitigation of voltage sags in different parts of the network in this paper.

The paper is organized as follows: Section II presents the simulation results without using controllers. Mitigation of the voltage sags in different parts of the network for the two cases (i.e. when voltage sag of $28 \%$ and $12 \%$ is proposed by using appropriate controllers in section III. Finally, the conclusion about the paper is presented in section IV.

\section{SIMULATION RESULTS WITHOUT USING CONTROLLERS}

A three phase fault with a fault impedance of $1 \Omega\left(Z_{f}=1 \Omega\right)$ is applied at time $\mathrm{t}=5 \mathrm{~s}$ on the Medium Voltage (MV) bus and is cleared after $150 \mathrm{~m}$ s. Since a three phase fault is a symmetric fault, and this kind of fault affects the voltage in all three phases equally. In this kind of fault only positive sequence component of the voltage is considered. The positive sequence component of the voltage on MV bus decreases to a value of 0.72 p.u (i.e. it is voltage sag of $28 \%$ ) as shown in "Fig." 2.

This kind of fault also causes voltage sag in different parts of the CIGRE network. Voltage sag is IEEE term which refers to percent decrease in voltage [6]. The voltage on bus $\mathrm{A}$, bus $\mathrm{B}$, bus C, bus D, bus E, R11 and bus R17 without compensation is shown in fig. 3 .
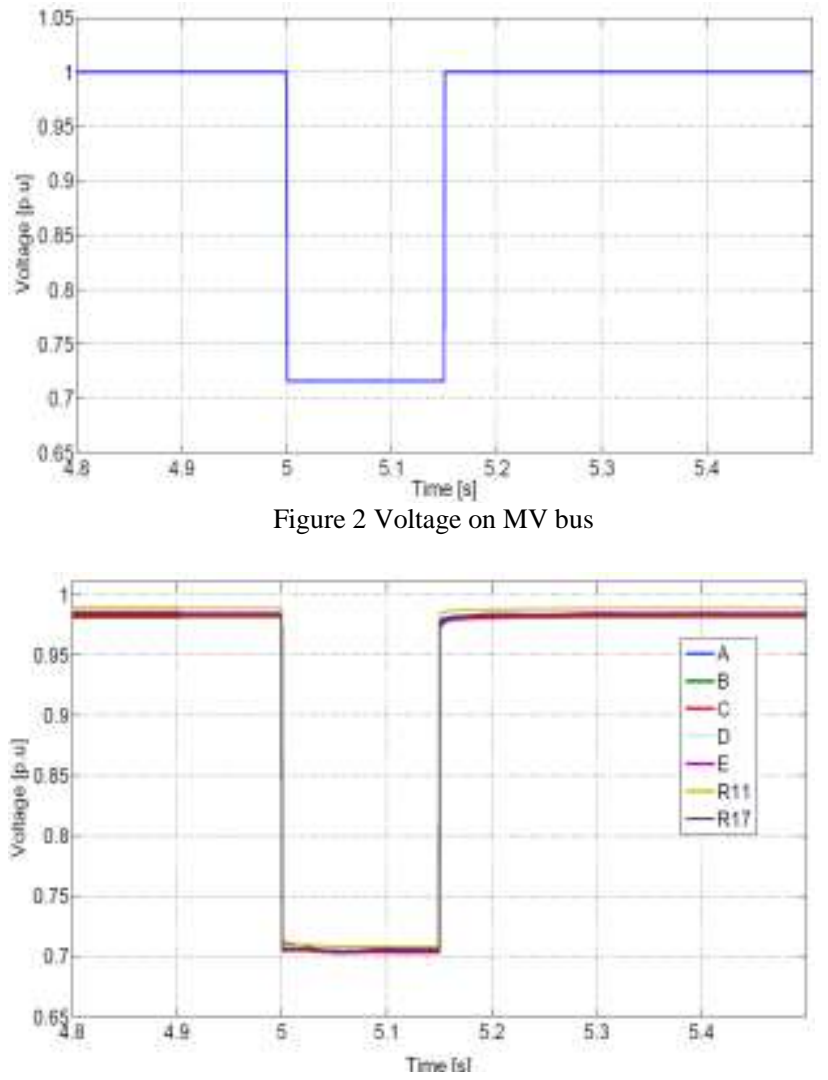

Figure 3. Voltage sag on different parts of network due to fault on MV bus

The depth of the voltage sag on different buses depends on the amount of current delivered by the grid and DG units and the network impedances between the fault and the current sources. The voltage sags are undesirable and cause adverse affects on different equipments used in power system. The behaviour of different components of CIGRE network during voltage sag is different.

The behavior of the wind turbine generator in the case of voltage sag depends on its technology. The $5.5 \mathrm{~kW}$ squirrel cage induction generator is used for the fixed pitch and fixed speed WTG for this study and is connected at bus E where voltage sag has been appeared. In the case of squirrel cage induction generator, there is a decrease in active power supplied to the grid due to the voltage sag. Similarly, the reactive power consumed by the machine is reduced due to the demagnetization of the generator. The severity of demagnetization depends of the depth of sag. When the fault is cleared the induction generator absorbs reactive power from the grid for its magnetization [7], [8]. Further, the mechanical torque of the machine is considered to be constant at constant wind speed and the voltage sag causes a reduction in the electrical torque which increases the speed of the generator [8]. If the over speed protection of the wind turbine limit is reached, the WTG has to be disconnected from the grid and stopped. This situation leads to an interruption of the production.

The detailed study about the effects of the voltage sags (i.e. symmetric or asymmetric) on WTG and its over speed 
protection in case of islanding is under the further consideration of the author.

The unbalanced loads are also connected at bus C, D, R11 and bus R17 of CIGRE network shown in "Fig." 1. Any deviation in the voltage adversely affects them. A sag in the voltage reduces the illuminating intensity of lighting loads. The effects of voltage sag are different for the different loads. The adverse effects of the voltage sag on sensitive house hold loads have been described in [9].

Similarly, voltage sag on the AC terminals of PV inverters causes the reduction in its DC-link voltage which in turn decreases the power output of PV units.

It is therefore, necessary to protect distribution system against voltage sags by using appropriate compensation devices.

\section{MitigATION OF VOLTAGE SAGS BY USING STACOM COMPENSATORS}

When STATCOM is used in distribution systems it is called D-STATCOM. It utilizes a design consisting of an IGBT based VSC connected to the power system and exhibits high speed control of reactive power to provide voltage stabilization in distribution networks. It can protect distribution networks against voltage sags by injecting the required amount of reactive power. According to EN 50160 standards the voltage tolerance limit in low voltage Danish distribution network is $+-10 \%$ [10].

Four D-STATCOMs, with proper controllers are employed at bus A, B, C and bus D. Two of them are used for PV applications and are only injecting/absorbing reactive power and the other two are equipped with batteries in order to inject/absorb both the active and reactive powers. These controllers are responsible for the voltage stabilization of the whole CIGRE network together with the external grid. Each D-STATCOM controller comprises two outer and two inner PI controllers and are detailed described in [5]. The two PV outer controllers are responsible for maintaining the $\mathrm{AC}$ and DC-link voltages. The inverters of the two BESSSTATCOMs are named VSC1 and VSC2 and are connected at bus $\mathrm{A}$ and $\mathrm{B}$ respectively. The inverters of the two PV STATCOMs are named VSC3 and VSC4 and are connected at bus $\mathrm{C}$ and $\mathrm{D}$, respectively.

The voltage in the network is restored back to the permissible limits by the injection of reactive power by the controllers during a fault. All four controllers participate in the compensation of the voltage sag by delivering reactive power. The voltages on the AC and DC sides of bus C and bus D are shown in "Fig." 4. It can be seen in "Fig." 4 that the DC-link voltages of VSC3 and VSC4 decrease due to the voltage sag at a time equal to $5 \mathrm{~s}$. A decrease in these voltages cause the power outputs of PV1 and PV2 delivered to the DC terminals of the respective inverters to decrease as shown in "Fig." 5.

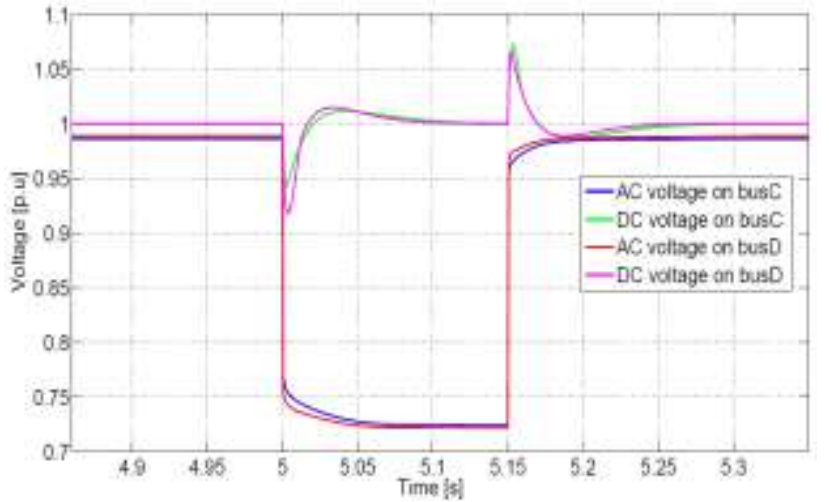

Figure 4 The DC-link voltage of VSC3 and VSC4 and voltage on AC side of bus $\mathrm{C}$ and bus $\mathrm{D}$

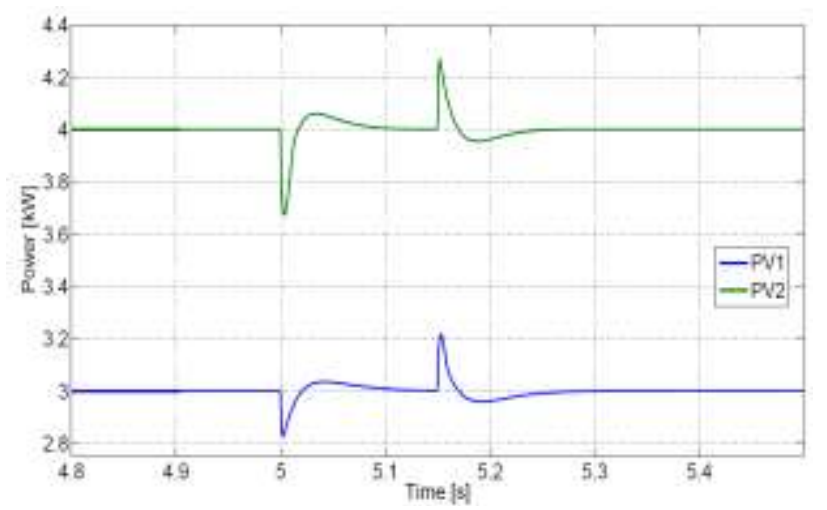

Figure 5 Power output of PV1 and PV2 on DC side of the VSC3 and VSC4

It can be seen in "Fig." 5 that PV1 and PV2 are producing rated powers (i.e. $3 \mathrm{~kW}$ and $4 \mathrm{~kW}$ ) respectively in normal operating conditions (i.e. full sunny day) and decrease when voltage sag appears at $\mathrm{t}=5 \mathrm{~s}$.

The DC-link capacitors connected at the DC sides of VSC3 and VSC4 are used to provide temporary injection or absorption of active power in order to control the DC-link voltages and thereby active power outputs of PV1 and PV2.

The DC voltage controller of the D-STATCOM controllers compares the actual and the reference value (i.e. 1 p.u) of the DC-link voltage and sends the error signal to the PI controller. The PI controller makes the error signal equal to zero and decides the amount of active power injection or absorption by the DC-link capacitor.

At $t=5 \mathrm{~s}$ the DC-link voltages (shown in "Fig." 4) and power outputs of PV1 and PV2 (shown in "Fig." 5) decrease and the respective controllers send signals to the capacitors to discharge and deliver the active powers. It is shown in "Fig." 4 and "Fig." 5 that the DC voltage controllers have controlled the DC-link voltages and maintained the power outputs of PV1 and PV2 at its pre-fault value in a short duration.

When a fault is cleared after $150 \mathrm{~m} \mathrm{~s}$, the DC-link voltages shown in "Fig." 4 increase because of the short time availability of active power injection by the capacitors until they return to charging mode. This peak in DC-link voltage causes the active power output of these units to increase as shown in "Fig." 5. When the DC-link voltages are brought 
back to nominal values, the productions of these units come to the nominal value again.

The voltage on the AC side of the buses in the network is improved by delivering the proper amount of reactive power. The AC voltage controllers of the D-STATCOMs are developed to meet these requirements. The controllers are developed in such a way that they are responsible to bring the AC voltage back to 1 p.u after any disturbance depending on the availability of reactive power.

The reactive powers injected by VSC1 and VSC2 when their respective controllers charge the batteries at full charging rates and the reactive power delivered by VSC3 and VSC4 are shown in "Fig." 6 and "Fig." 7 respectively. The contribution of reactive power from the different converters (i.e. VSC1, VSC2, VSC3 and VSC4) is according to their rated power. The ratings of inverters used in the network are shown in Table. 1.

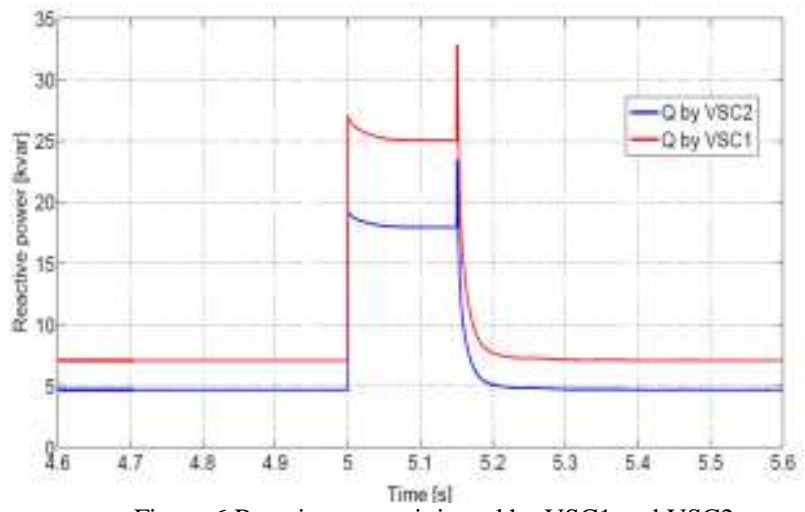

Figure 6 Reactive power injected by VSC1 and VSC2

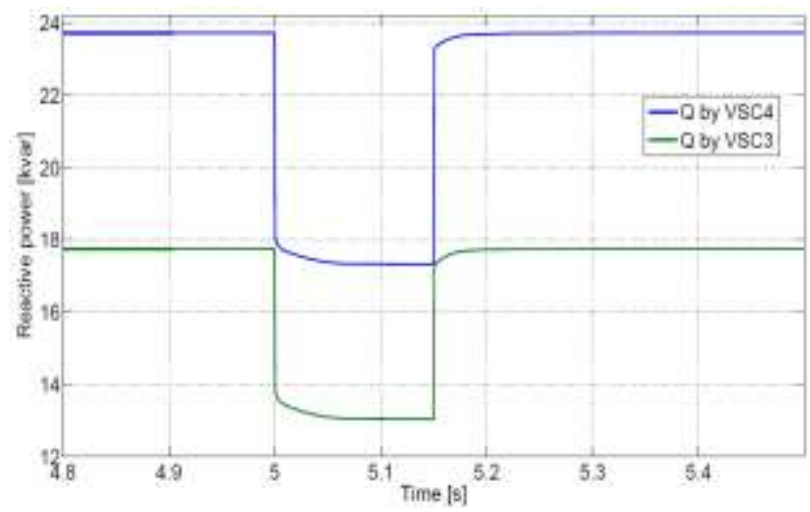

Figure 7 Reactive power injected by VSC3 and VSC4

TABLE 1

THE RATINGS OF THE INVERTERS USED IN THE NETWORK

\begin{tabular}{cc} 
Name of an inverter & Apparent power, S (kVA) \\
\hline VSC1 1 & 35 \\
VSC2 & 25 \\
VSC3 & 18 \\
VSC4 & 24 \\
\hline
\end{tabular}

The inverters mentioned in Table 1 can deliver reactive power up to their rated value if they do not inject or absorb active power. As shown in "Fig." 6, VSC1 and VSC2 deliver small amounts of reactive power during steady state condition but inject maximum amount of reactive power during voltage sag. It can be seen in "Fig." 7 that VSC3 and VSC4 are injecting nearly full amount of reactive power in steady state operation in order to meet the line voltage drops and other load unbalances in the network. The reactive power delivered by these controllers is not enough to restore the voltage on these buses to 1 p.u during steady state operation, therefore when the voltage sag appears at $\mathrm{t}=5 \mathrm{~s}$, the controllers do not have enough reactive power to compensate for it and hence the distribution system operates in under voltage condition. Due to this reason the reactive power injected by these controllers decrease further (i.e. $Q=V I \sin \varphi$ ) as seen in "Fig." 7.

The voltage on bus A, B, C, D, bus E, R11 and bus R17 in this case is shown in "Fig." 8 . It can be seen in "Fig." 8 that all the controllers in the CIGRE test network are not able to compensate the voltage sag up to desirable operating limits.

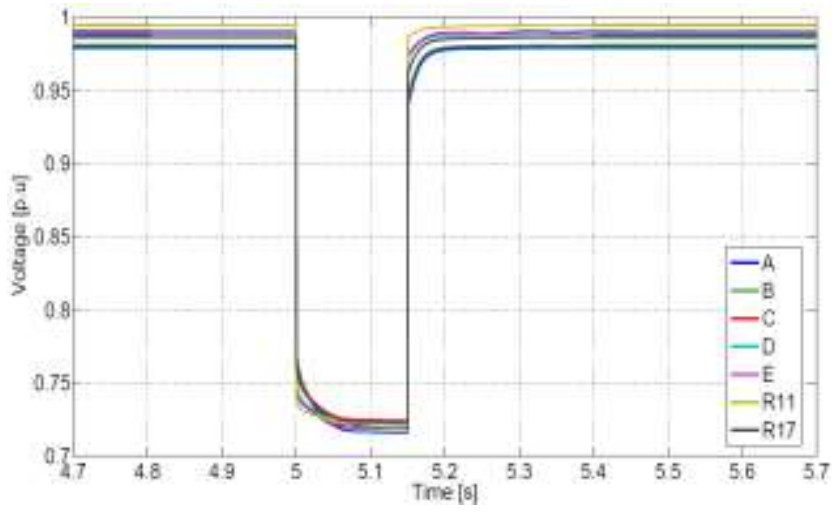

Figure 8 Voltage on different parts of network with compensation

On the other hand, the voltage sags in the distribution network can be mitigated to acceptable limits if batteries are charged at low rates instead of at full rates. The plots of the current drawn by both the batteries from the grid for two different charging rates (i.e. $1 \mathrm{C}$ rate and $1 / 10 \mathrm{C}$ rate) flowing through line L2 and line L4 is shown in "Fig." 9 and "Fig." 10 respectively.

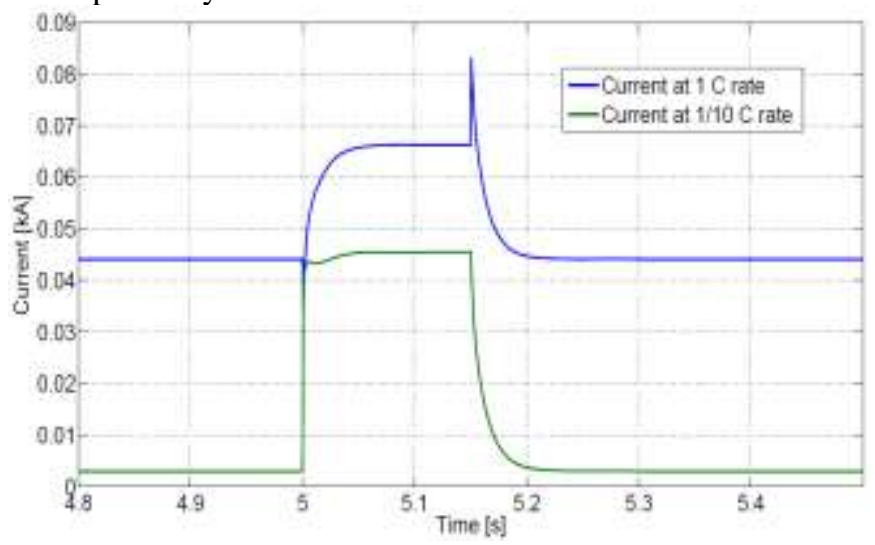

Figure 9 current through line L2 for the two different charging rates 


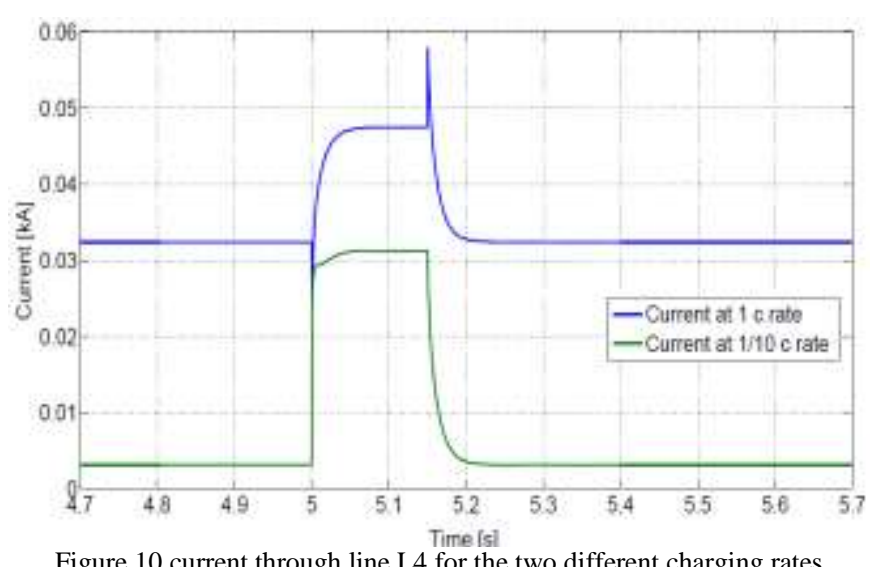

Figure 10 current through line L4 for the two different charging rates

It can be seen in "Fig." 9 and "Fig." 10 that both batteries carry different currents at different charging rates during steady state operation. The batteries are charged slowly when current flows according to $1 / 10^{\text {th }}$ rate. The current flowing through these lines increases when the short circuit fault occurs at $\mathrm{t}=5 \mathrm{~s}$ in the network. The increase in the current through these lines during a fault at a slower charging rate is less as compared to a faster one and gives less voltage drop across the lines.

The voltage on bus A, bus B, bus C, bus D, bus E, R11 and bus R17 in this case is shown in "Fig." 11 . The voltage seen on bus $\mathrm{C}$ during voltage sag is oscillating and these oscillations are due to the behavior of the reactive power absorbed/injected by WTG. It can be seen in "Fig." 11 that the voltage in the low voltage CIGRE network has been improved a little but the existing controllers are still unable to compensate the voltage sags of this depth up to the desired level.

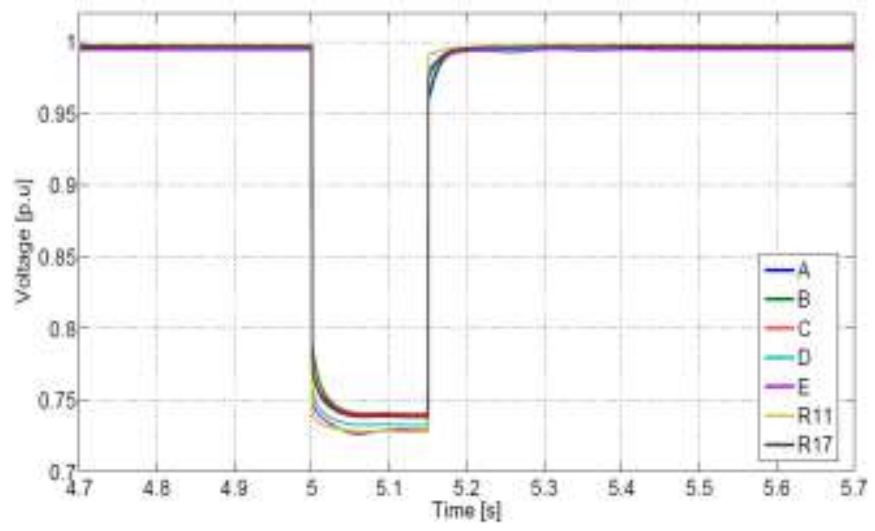

Figure 11 Voltage on different parts of the network with compensation when batteries are charged at $1 / 10$ th charging rate

Alternately, a three phase fault with a fault impedance of $2 \Omega$ $\left(Z_{f}=2 \Omega\right.$ ) is applied at time $\mathrm{t}=5 \mathrm{~s}$ on the MV bus instead.

This is done in order to test the effectiveness of the controllers for less deep voltage sags as compared to previous case. The voltage on the MV bus and the voltage sag in the other parts of network without using controllers are shown on "Fig." 12 and "Fig." 13 respectively.

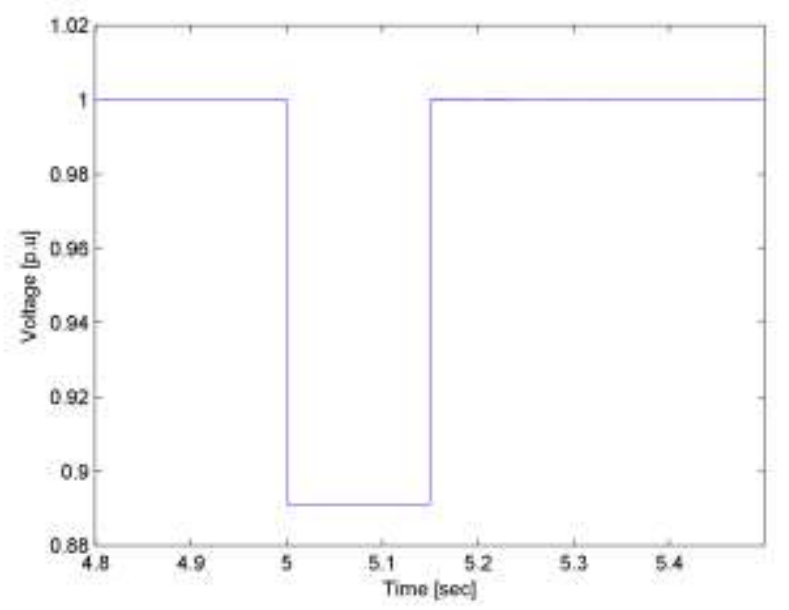

Figure 12 Voltage on MV bus when fault appears with $2 \Omega$ fault impedance

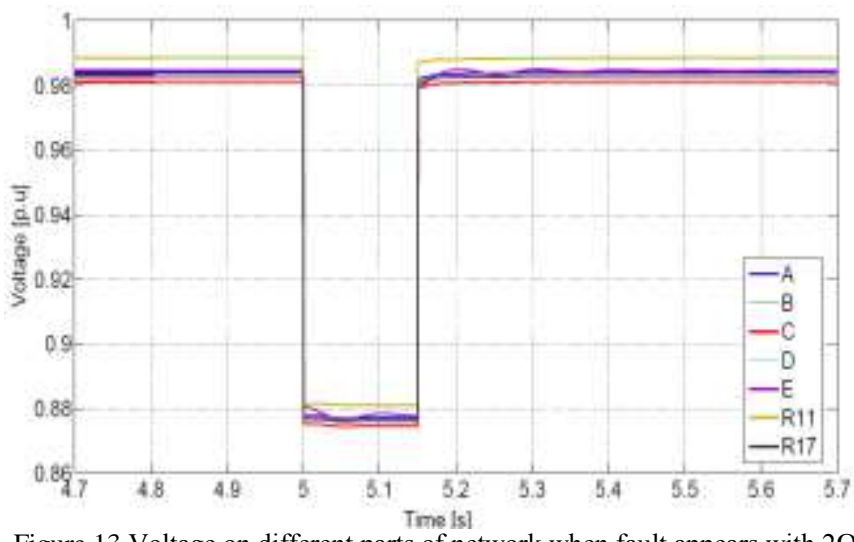

Figure 13 Voltage on different parts of network when fault appears with $2 \Omega$ fault impedance

The positive sequence component of voltage on MV decreases to a value of 0.88 p.u (i.e. voltage sag of $12 \%$ ) in this case as shown in "Fig." 12. The sag depth is shallow because of bigger fault impedance as compared to the previous case. In can be seen in "Fig." 13 that the voltage sag on bus R11 is slightly less than on the other buses because there is less current flow in that direction as the three single phase loads on that bus are small as compared to the other existing loads in the network.

The compensation in this case is made when all four controllers are injecting reactive power in order to maintain the quality of power in the network. The voltage on different buses of the network when batteries are charged at full charging rates is shown in "Fig." 14. It can be seen in this fig. that the voltage in the network is improved but it is still less than the power quality limits for Danish low voltage grids [10].

By implementing the method of slow charging of the batteries, the voltage in the network has been restored to the permissible limits according to Danish standards as shown in "Fig." 15. 


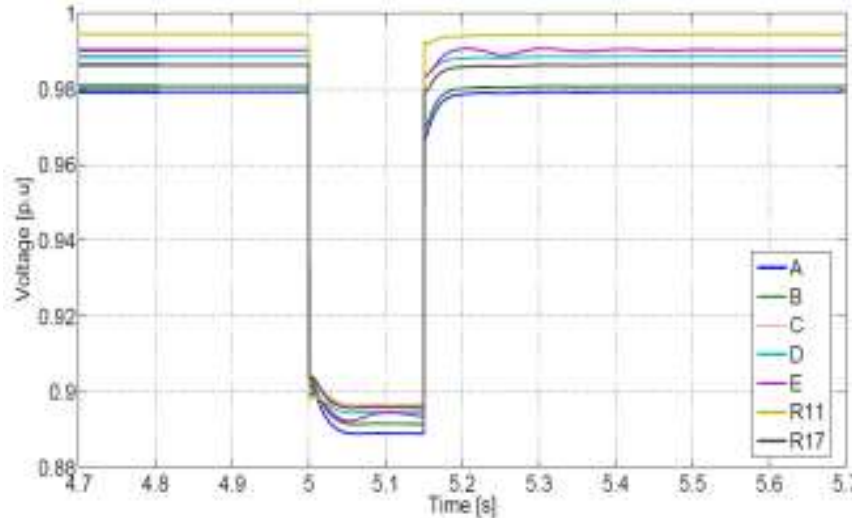

Figure 14 Voltage on different parts of network when batteries charge at full charging rate

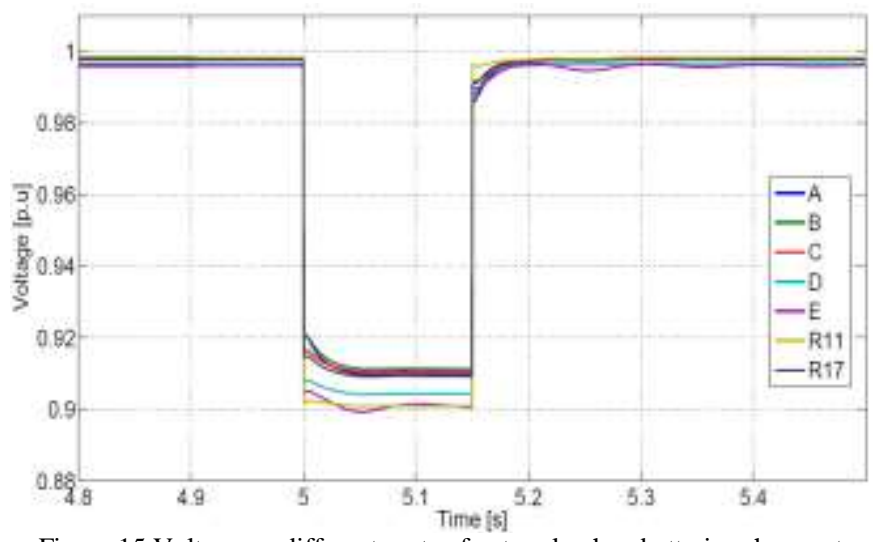

Figure 15 Voltage on different parts of network when batteries charge at slow rate

The D-STATCOM controller of battery2 and STATCOM controller of PV1 are delivering reactive power which is summed up at the same connection point (i.e. R10 in "Fig." 1). This is the reason why the voltage on the buses of these controllers (i.e. bus B and Bus C) is improved more than the other buses as shown in "Fig." 15. The voltage on Bus B during voltage sag is improved slightly better than the voltage on bus $\mathrm{C}$ because of a higher rating of an inverter (i.e. VSC2) used on bus $\mathrm{B}$ which delivers more reactive power as compared to the inverter on bus C (i.e. VSC3).

The sum of the reactive power of the above mentioned controllers passing through point R10 flows to other parts of the network in order to compensate the voltage sags there. The remaining amount of reactive power after the compensation of voltage sag on bus R17 flows towards the other parts of network again where it adds with the reactive power delivered by the STATCOM controller of battery 2 and the STATCOM controller of PV2 and corrects the voltage on the other buses.

\section{CONCLUSION}

A brief introduction about the effects on voltage sags on WTG, the loads and on the output power of PV units have been presented in this paper. The mitigation of voltage sag has been performed by using two D-STATCOM and two BESS based STATCOM controllers. The compensation for the two different cases (i.e. voltage dip of $72 \%$ and $88 \%$ ) has been performed. It has been shown that when batteries are charged at full charging rates, controllers have not enough reactive power to compensate the voltage sag to a satisfactory limit. It is concluded that the mitigation of voltage sags in this network by using existing services is only possible if batteries are charged at slow rate. The batteries have been charged at slow rates for the two cases in order to mitigate the voltage sag in the network to the permissible limits. It has been observed that the existing controllers can mitigate the voltage dip of up to $88 \%$ depth. If the depth of the voltage dip is more than that the controllers cannot restore the voltage up to the operating limits. This has been verified in simulation results. In future work the controllers will be tested in island conditions as well. The effects of different types of voltage sags on the WTG and its protection against over speeding of the generator in island operation will be studied in future.

\section{ACKNOWLEDGMENT}

The authors are thankful to Kai Strunz for providing the CIGRE test network for LV distribution network. I, Ghullam Mustafa am thankful to Quaid-E-Awam University of Engineering Sciences and Technology, Nawabshah, Sindh, Pakistan for the support and funding.

\section{REFERENCES}

[1] Joe H, Chow, Felix F. Wu and James Momoh, "Applied Mathematics for restructured electric power sysyetms, optimisation, control, and computational intelligentce," Power electronics and power systems 2005: pp $11-24$.

[2] T. Devaraju, Dr. V.C. Veera Reddy and Dr. M. Vijaya Kumar, "Role of custom power devices in Power quality enhancement: A review," trans. on Engineering Sciences and Technology, Vol. 28, pp. 3628-3634, 2010.

[3] Massimo Bongiorno, "Control of voltage source converters for voltage dip mitigations for shunt and series configurations," $\mathrm{PhD}$ dissertation; Department of Energy system, Chalmers University of Technology; Sweden: Gothenburg, 2007.

[4] Benchmark Systems for Network Integration of Renewable Energy Resources, version 7, March2011, CIGRE Task force C6.04.02.

[5] Ghullam Mustafa, Birgitte Bak-Jensen and Pukar Mahat, "Modeling of the CIGRE low voltage test distribution network and the development of appropriate controllers," in trans. of Smart Grid and Clean Energy, vol. 2, no. 2, pp. 184-191, May 2013.

[6] Terry Chandler. "The effects of voltage sags," IEEE Hong Kong Section, May 31, 2002

[7] Bousseau P, Gautier E, Garzulino I, Juston P, Belhomme R, "Grid impact of different technologies of wind turbine generator systems," in Proc. On EWEC03, June 2003

[8] Dittrich A, "Grid Voltage Fault Proof Doubly Fed Induction Generator System," EPE 03, Toulouse 2003

[9] George G. Karady, Saurabh Saksena, and Bauzhuang Shi, "Effects of voltage sags on house hold loads," IEEE Power Engineering Society General Meeting, Vol. 3, pp. 2456-2461, 2005.

[10] Rekommandation 16, Spændingskvalitet I lavspændingsnet (voltage quality in low voltage networks), 4. Udgave, Aug. 2011. 